\title{
The appearance-reality distinction and perspective taking with facial masks
}

\author{
DOROTHY M. GRALOW, ANNE C. CUNNINGHAM, CURTIS W. MCINTYRE, \\ and STAN A. KUCZAJ II \\ Southern Methodist University, Dallas, Texas
}

\begin{abstract}
Little is known about how children perceive themselves while wearing facial masks; how they perceive another person who is wearing a facial mask; or how they believe another person perceives them when they are wearing facial masks. This aspect of the appearance-reality distinction was studied in 60 children, 20 in each of three age groups: 4, 4.5, and 5.5 years old. Each child responded to both an appearance question (“... looks like?") and a reality question (“... really and truly?") on each of four trials. Three of the trials involved wearing masks (Wonder Woman, Spiderman, or Bugs Bunny) but the other did not. Each child answered the eight appearance-reality questions under three perspective-taking conditions: self (what the child perceived while looking in a mirror), other (what the child perceived while looking at another), and other's perspective (what another perceived while looking at the child). In general, the results suggest that the appearance-reality distinction and simple perspective taking are well established by the age of 5.5 years, and that correct responses to reality questions emerge earlier than correct responses to appearance questions.
\end{abstract}

The development of children's abilities to distinguish between appearance and reality has been the subject of considerable research in recent years. De Vries (1969) performed one of the first experiments that involved children's abilities to distinguish appearance from reality. In this study, the child's concept of generic identity, or reality, was tested. To do this, De Vries used a cat named Maynard, a dog mask, and a rabbit mask. She tested the children's ability to distinguish between appearance and reality by placing the masks on Maynard and asking the children questions about what animal Maynard was and what type of food he could eat. De Vries found a developmental pattern: Three-year-olds were not able to respond consistently and accurately to the questions; 6-years-olds were.

Another early study of children's developing abilities to distinguish between appearance and reality involved the presentation of pictures reflecting fantasy (animals performing human actions) and nonfantasy situations (humans and animals performing species-appropriate actions). Using these stimuli, Taylor and Howell (1973) asked children between the ages of 3 and 5 years to look at the pictures and to indicate whether the events represented in them could or could not really occur. As in the De Vries (1969) study, 3-year-olds answered the questions poorly, whereas 6-year-olds did much better.

Much of the recent research on the appearance-reality distinction has been generated by John Flavell and his colleagues. Seven different experiments on children's abili-

Correspondence should be addressed to Curtis W. McIntyre, Psychology Department, Southern Methodist University, Dallas, TX 75275-0442. ties to distinguish between appearance and reality were reported by Flavell, Green, and Flavell (1986), who used a variety of modalities and various perspective-taking conditions. They focused on trying to improve the performance of the 3-year-olds. Controlling for pretraining, memory effects, and language, Flavell et al. (1986) and Flavell, Green, Whal, and Flavell (1987) found a slight improvement in the 3-year-olds' performance when the language used in the task was simplified; however, the improvement was not significant. Neither memory nor pretraining affected the performance of the 3-year-olds. Simplifying the task itself was also tried, in an attempt to improve the performance of 3-year-olds (Flavell, 1986). Familiar visual objects were used to improve the children's understanding of the task (one example of such an object was a glass of milk that had its color changed from white to blue). In some tasks, parts of an object were left uncovered so that the children could see its real color; in others, appearance and reality questions were juxtaposed, to contrast the answers more clearly. Despite these simplifications, the 3-year-olds still performed poorly.

To date, all research on the appearance-reality distinction has revealed a straightforward developmental trend. Three-year-olds experience considerably more difficulty in distinguishing between appearance and reality than 5year-olds do, regardless of the type of task (De Vries, 1969; Flavell et al., 1986; Gopnik \& Astington, 1988; Taylor \& Howell, 1973). Two types of errors are seen in all children from 3 to 5 years of age, but they are more common to younger children placed in appearance-reality situations (Flavell, Flavell, \& Green, 1983; Flavell et al., 1986; Gopnik \& Astington, 1988; Liben \& Belknap, 1981; Taylor \& Flavell, 1984). The first type 
of error involves "phenomenism"- -responding with appearance when reality is correct; the second type of error involves "intellectual realism"-responding with reality when appearance is correct.

These developmental patterns and errors have also been found when children have been asked to respond to appearance-reality questions about another person who was wearing (or not wearing) a mask (Flavell et al., 1986). However, little is known about how children perceive themselves while wearing facial masks, or about how they believe another perceives them when they are wearing facial masks. In the present study, the developing abilities of 4-, 4.5-, and 5.5-year-old children to distinguish between appearance and reality were studied with a task that involved facial masks and three different role-taking perspectives. Sixty children (20 in each of three age groups: $4,4.5$, and 5.5 years) responded to both an appearance question (“... looks like?") and a reality question ("... really and truly?") on each of four trials. Three of the trials involved wearing facial masks (Wonder Woman, Bugs Bunny, and Spiderman), but the other did not. Each child answered the eight appearance-reality questions in three different perspective-taking conditions: self (what the child perceived while looking in a mirror); other (what the child perceived while looking at another); and other's perspective (what the child thought another perceived while looking at the child).

The age range of 4-5.5 years was selected so that we could examine the possibility that the appearance-reality distinction would develop within this age range. However, no specific predictions were made concerning either the order of emergence of appearance and reality or the interaction of perspective-taking conditions with the appearance and reality distinction.

\section{METHOD}

\section{Subjects}

The subjects were 60 nursery school children from middle-class and upper-middle-class backgrounds. They were divided into three age groups of 20 children each: 4 -year-olds (mean age $=4.1$, range $=3.8-4.4$ ), 4.5-year-olds (mean age $=4.8$, range $=4.5-4.9$ ), and 5.5-year-olds (mean age $=5.5$, range $=5.0-6.0$ ). There were equal numbers of males and females in each group.

\section{Materials}

Four masks (Mickey Mouse, Wonder Woman, Spiderman, and Bugs Bunny), a $5 \times 7$ in. mirror, and a $5 \times 7$ in. open mirror frame were used. The masks were brightly colored, plastic, full facial masks that slipped easily over each child's head and completely covered the child's face. The masks were held in place by an elastic band around the back of the head. The mirror was held directly in front of the child's face by the second experimenter at a distance of approximately 12 in., so that the child could see the reflection of his or her face (mask). The mirror frame was held directly in front of the second experimenter's face at a distance of approximately 12 in., so that the second experimenter's face (mask) was framed. After participation, each child chose a small party-favor prize as a reward.

\section{Procedure}

Each child was tested individually by two experimenters. The first experimenter (female) asked questions and recorded the responses; the second experimenter (male) assisted with the masks, mirror, and frame.
Pretraining. The first experimenter established rapport by engaging each child in an informal conversation about Halloween. The child was asked to describe the costume worn on Halloween with specific questions asked about the child's facial appearance. The contrast between appearance (how the child looked) and reality (who the child was really and truly) was emphasized. Additional emphasis was placed on the idea that "sometimes things could look one way" to the child's eyes while they were "really and truly a different way."

Following this conversation, the child was asked to put on the Mickey Mouse mask and to look in a mirror held by the second experimenter. The first experimenter said, "When you look at yourself in the mirror right now, you look like a mouse. But you really and truly aren't a mouse." Then, the second experimenter removed the mask while the first experimenter said, "You're really and truly [child's name]." This sequence was repeated twice, with the first experimenter saying, "Sometimes things look one way to your eyes," while the child was wearing the mask, and "when they really and truly are a different way," after the second experimenter removed the mask from the child's face.

Testing. Each child responded to both an appearance question (". . . looks like?") and a reality question ("... really and truly?") on each of four trials. Three of the trials involved the wearing of a mask (Wonder Woman, Spiderman, and Bugs Bunny), but the other did not.

Each child answered these eight appearance-reality questions under three perspective-taking conditions: self (what the child perceived while wearing a facial mask and looking into a mirror held by the second experimenter); other (what the child perceived while looking at the second experimenter who was wearing a facial mask and holding the open frame in front of his face); and other's perspective (what the child thought the second experimenter perceived while looking at the child who was wearing a facial mask and looking in the mirror). Each child answered a total of 24 questions.

\section{Perspective-Taking Conditions}

Self. When the child was wearing the Bugs Bunny mask and looking directly at his or her own reflection in the mirror held by the second experimenter, the first experimenter asked the appearance question as follows: "When you look in the mirror with your eyes right now do you look like [child's name or Bugs Bunny] or do you look like [child's name or Bugs Bunny]?" The reality question was worded as follows: "When you look in the mirror with your eyes right now who is it really and truly? Is it really and truly [child's name or Bugs Bunny] or is it really and truly [child's name or Bugs Bunny]?"

Other. When the second experimenter was wearing the Bugs Bunny mask and the child was looking through the mirror frame directly at the second experimenter, the first experimenter asked the appearance question as follows: "When you look through the frame with your eyes right now, does it look like [experimenter's name or Bugs Bunny] or does it look like [experimenter's name or Bugs Bunny]?" The reality question was worded as follows: "When you look through the frame with your eyes right now, is it really and truly [experimenter's name or Bugs Bunny] or is it really and truly [experimenter's name or Bugs Bunny]?’'

Other's perspective. When the child was wearing the Bugs Bunny mask, looking directly at his or her reflection in the mirror, and asked how he or she (the child) appeared to the second experimenter, the first experimenter asked the appearance question as follows: "Look in the mirror now. When he looks at you with his eyes right now, who does he see? Does he see [child's name or Bugs Bunny] or does he see [child's name or Bugs Bunny]?" The reality question was worded as follows: "Look in the mirror now. When he looks at you with his eyes right now, who is it really and truly? Is it really and truly [child's name or Bugs Bunny] or is it really and truly [child's name or Bugs Bunny]?,

For all three perspective-taking conditions, the order of the appearancereality questions and the order of the possible responses (child's name or mask's name) were randomized for each subject. The same questions were used when the child was not wearing a mask (no-mask condition). Similar questions were used for the other two masks with the other masks' names substituted as possible answers. Between questions, the first experimenter said, "Now, here is a different question!" 
Table 1

Mean Number of Correct Responses to Appearance-Reality Questions in the Three Perspective-Taking Conditions

\begin{tabular}{|c|c|c|c|c|c|c|c|c|c|c|}
\hline \multirow[b]{3}{*}{ Age } & \multicolumn{9}{|c|}{ Perspective-Taking Conditions } & \multirow[b]{3}{*}{ Total $M$} \\
\hline & \multicolumn{3}{|c|}{ Self } & \multicolumn{3}{|c|}{ Other } & \multicolumn{3}{|c|}{ Other's Perspective } & \\
\hline & App. & Real. & $M$ & App. & Real. & $M$ & App. & Real. & $M$ & \\
\hline 4.0 & 2.65 & 2.80 & 2.73 & 2.15 & 3.10 & 2.63 & 2.75 & 2.75 & 2.75 & 2.70 \\
\hline 4.5 & 2.95 & 3.60 & 3.28 & 3.00 & 3.40 & 3.20 & 2.80 & 3.50 & 3.15 & 3.21 \\
\hline 5.5 & 3.65 & 3.85 & 3.75 & 3.75 & 3.85 & 3.80 & 3.70 & 3.80 & 3.75 & 3.77 \\
\hline$M$ & 3.08 & 3.42 & 3.28 & 2.97 & 3.48 & 3.21 & 3.08 & 3.38 & 3.22 & 3.23 \\
\hline
\end{tabular}

\section{RESULTS}

A 3 (age groups) $\times 3$ (perspective-taking conditions) $\times 2$ (questions) analysis of variance applied to the correct responses revealed a significant main effect for age group $[F(2,57)=17.14, p<.001]$ and a significant age group $\times$ perspective-taking condition $\times$ question interaction $[F(4,114)=2.52, p<.05]$. Newman-Keuls multiple comparison tests applied to the significant main effect for age group revealed significant differences between the means obtained for all three groups. For the 4-, 4.5-, and 5.5-year-old age groups, the means were 2.70, 3.21, and 3.77 , respectively (see Table 1 ).

The significant age group $\times$ perspective-taking condition $\times$ question interaction and subsequent single-sample $t$ tests against chance (2) and perfect performance (4) indicated the following. First, the 4-year-olds did not depart significantly from chance in responding to the appearance questions; they departed from chance only in responding to the reality questions under one perspective-taking condition (other). Second, the 4.5-year-olds departed signifi- cantly from chance in responding to the appearance questions under two perspective-taking conditions (self and other) but were almost perfect in responding to the reality questions under all three perspective-taking conditions. And third, the 5.5-year-olds were almost perfect in responding to the appearance and the reality questions under all three perspective-taking conditions (see Table 2).

A frequency analysis of perfect and random response patterns is presented in Table 3; the same pattern as that of the previous data can be seen. Overall, the 4-year-olds answered with no consistent pattern; some responded at random, whereas others responded perfectly to all questions. The 4.5-year-olds showed the same split on the appearance and the reality questions; answers to the appearance questions were about equally divided between chance and perfect responses, but on the reality questions, almost all 4.5-year-olds responded perfectly. Almost all the 5.5year-olds answered with perfect responses; only a few responded randomly.

Additional analyses of variance failed to reveal significant effects for masks, gender, or any of their interactions.

Table 2

Results of Single-Sample $t$ Tests Contrasting the Mean with Chance (2) and Perfect Performance (4) on Appearance-Reality Questions in the Three Perspective-Taking Conditions

\begin{tabular}{|c|c|c|c|c|c|c|}
\hline \multirow[b]{3}{*}{ Age } & \multicolumn{6}{|c|}{ Perspective-Taking Conditions } \\
\hline & \multicolumn{2}{|c|}{ Self } & \multicolumn{2}{|c|}{ Other } & \multicolumn{2}{|c|}{ Other's Perspective } \\
\hline & App. & Real. & App. & Real. & App. & Real. \\
\hline 4.0 & $\begin{array}{c}2=M<4 \\
\text { chance }\end{array}$ & $\begin{array}{c}2=M<4 \\
\text { chance }\end{array}$ & $\begin{array}{c}2=M<4 \\
\text { chance }\end{array}$ & $\underset{\text { neither }}{2<M<4}$ & $\begin{array}{c}2=M<4 \\
\text { chance }\end{array}$ & $\begin{array}{c}2=M<4 \\
\text { chance }\end{array}$ \\
\hline 4.5 & $2<\underset{\text { neither }}{2}$ 作 & $\begin{array}{c}2<M=4 \\
\text { perfect }\end{array}$ & $\underset{\text { neither }}{2<M<4}$ & $\begin{array}{c}2<M=4 \\
\text { perfect }\end{array}$ & $\begin{array}{c}2=M<4 \\
\text { chance }\end{array}$ & $\begin{array}{c}2<M=4 \\
\text { perfect }\end{array}$ \\
\hline 5.5 & $2<\underset{\text { perfect }}{2}$ & $\underset{\text { perfect }}{2<M=4}$ & $2<\underset{\text { perfect }}{2}$ & $2<\begin{array}{c}2<M=4 \\
\text { perfect }\end{array}$ & $2<\underset{\text { perfect }}{2<M=4}$ & $2<\underset{\text { perfect }}{2<M=4}$ \\
\hline
\end{tabular}

Table 3

Frequency Analysis of Perfect and Random Response Patterns on Appearance-Reality Questions in the Three Perspective-Taking Conditions

\begin{tabular}{|c|c|c|c|c|c|c|c|c|c|c|c|c|}
\hline \multirow[b]{4}{*}{ Age } & \multicolumn{12}{|c|}{ Perspective-Taking Conditions } \\
\hline & \multicolumn{4}{|c|}{ Self } & \multicolumn{4}{|c|}{ Other } & \multicolumn{4}{|c|}{ Other's Perspective } \\
\hline & \multicolumn{2}{|c|}{ App. } & \multicolumn{2}{|c|}{ Real. } & \multicolumn{2}{|c|}{ App. } & \multicolumn{2}{|c|}{ Real. } & \multicolumn{2}{|c|}{ App. } & \multicolumn{2}{|c|}{ Real. } \\
\hline & $n_{1}$ & $n_{2}$ & $n_{1}$ & $n_{2}$ & $n_{1}$ & $n_{2}$ & $n_{1}$ & $n_{2}$ & $n_{1}$ & $\bar{n}_{2}$ & $n_{1}$ & $\overline{n_{2}}$ \\
\hline 4.0 & 7 & 7 & 10 & 8 & 5 & 12 & 11 & 4 & 7 & 8 & 10 & 6 \\
\hline 4.5 & 10 & 7 & 16 & 3 & 12 & 7 & 15 & 5 & 10 & 7 & 14 & 2 \\
\hline 5.5 & 15 & 1 & 18 & 1 & 17 & 1 & 19 & 1 & 18 & 2 & 18 & 1 \\
\hline Tot & 32 & 15 & 44 & 12 & 34 & 24 & 45 & 10 & 35 & 17 & 42 & 9 \\
\hline
\end{tabular}

Note $-n_{1}=$ number of children responding perfectly. $n_{2}=$ number of children responding randomly. 


\section{DISCUSSION}

This study reveals the same developmental pattern as has the previous research on the appearance and reality distinction (De Vries, 1969; Flavell, 1986; Flavell et al., 1983; Gopnik \& Astington, 1988; Taylor \& Howell, 1973). The 4-year-olds were not able to distinguish between appearance and reality consistently or accurately. They showed no consistent pattern of responses as a group. Rather, individual children would answer with a particular error type (e.g., responding entirely with the name of the mask - the "phenomenism" error; or responding entirely with their names-the "intellectual realism" error), whereas others responded at random.

However, an interesting trend occurred for the 4.5-year-olds. They answered the reality questions almost perfectly while still encountering difficulty with the appearance questions. Also, they tended to answer all the questions with their names (making the "intellectual realism" error), and they gave this answer consistently across all the perspectivetaking conditions. Evidently, 4.5-year-olds have a sense of the permanence of reality but are still unable to distinguish it from appearance effectively.

Also, as had been expected on the basis of the previous research, the 5.5-year-olds were able to distinguish between appearance and reality quite easily. In fact, they often interrupted the experimenter to answer the question. The experimenter would ask, "If you look in the mirror with your eyes right now who is it really and truly? Is ..." and the child would interrupt and say, "It's [child's name]." Clearly the 5.5year-olds understood the task and were able to answer the questions consistently and accurately.

In contrast to the separateness of emergence of appearance and reality, there is no separateness in the emergence of the perspective-taking conditions. Rather, once the children understand the distinction between appearance and reality, it quickly generalizes across all the perspectivetaking conditions. This is similar to Piaget's (1957) finding that once a child understands a simple conservation task (e.g., a quantity task involving the pouring of water from one container to another), the child is able to conserve across similar quantity situations without difficulty. However, the relationship between appearance-reality distinction skills and conservation skills is still not fully understood. Although the appearance-reality distinction and simple conservation tasks require similar abilities, appearance-reality distinction skills develop about 1 year earlier than conservation skills do. Perhaps the appearance-reality distinction reflects an early form of conservation.

In general, these results suggest that the appearance-reality distinction and simple perspective taking are well established by the age of 5.5 years. Clear, if somewhat brief, developmental patterns of emergence for appearance and reality are indicated by the transition from the chance performances of the 4-year-olds (where neither is established) to the almost perfect performances of the 5.5-year-olds (where both are established). The separateness of the developmental patterns for appearance and reality is indicated by the performance of the 4.5-year-olds who answered the reality questions almost perfectly while still encountering difficulty with the appearance questions. Their performances indicate that reality is established by 4.5 years of age, while appearance is still emerging. Reality and appearance are both established by 5.5 years of age, as is indicated by the almost perfect performances by the 5.5 -year-olds on both the appearance and the reality questions. More- over, this distinction quickly generalizes to all the perspective-taking conditions.

The appearance-reality distinction examined in this study is very basic and is limited to the physical realm. This ability to distinguish between physical appearance and physical reality continues to develop throughout an individual's lifetime, eventually encompassing social and psychological as well as physical realms. Although the basic ability to distinguish between physical appearance and reality seems to be well developed by the age of 5.5 years, the children's familiarity with facial masks may have played a part in the results. All the children in this study were familiar with facial masks and had access to costumes of some sort on a regular basis. Children who have little or no familiarity with facial masks or costumes may not perform as well on experiments of this type. Nonetheless, the developmental trends that were found, combined with the results of previous investigations, suggest that the concept of reality emerges before that of appearance. We suspect that the concept of reality is a prerequisite for the concept of appearance, for the knowledge that things are sometimes different than they seem requires a comparison of appearance with reality. If the concept of reality is not understood, this comparison is impossible.

\section{REFERENCES}

DE VRIES, R. (1969). Constancy of generic identity in the years three to six. Monographs of the Society for Research in Child Development, 34(3, Serial No. 127).

FlavelL, J. H. (1986). The development of children's knowledge about the appearance-reality distinction. American Psychologist, 41, 418-425.

Flavell, J. H., Flavell, E. R., \& Green, F. L. (1983). Development of the appearance-reality distinction. Cognitive Psychology, 15, 95-120.

Flavell, J. H., Green, F. L., \& Flavell, E. R. (1986). Development of knowledge about the appearance-reality distinction. Monographs of the Society for Research in Child Development, 51(1, Serial No. 212).

Flavell, J. H., Green, F. L., Whal, K. E., \& Flavell, E. R. (1987). The effects of question clarification and memory aids on young children's performance on appearance-reality tasks. Cognitive Development, 2, 127-144.

GopNIK, A., \& Astington, J. W. (1988). Children's understanding of representational change and its relation to the understanding of false belief and the appearance-reality distinction. Child Development, 59 , 26-37.

LiBEN, L. S., \& BELKNAP, B. (1981). Intellectual realism: Implications for investigations of perceptual perspective taking in young children. Child Development, 52, 921-924.

Piaget, J. (1957). Logic and psychology. New York: Basic Books.

Taylor, M., \& Flavell, J. H. (1984). Seeing and believing: Children's understanding of the distinction between appearance and reality. Child Development, 55, 1710-1720.

TAYLOR, B., \& HowELL, R. (1973). The ability of three-, four-, and five-year-old children to distinguish fantasy from reality. Journal of Genetic Psychology, 122, 315-318.

(Manuscript received January 10, 1991.) 